NOTES

\title{
Regioselectively Modified Stereoregular Polysaccharides VII. Synthesis of $(1 \rightarrow 6)-\alpha$-D-Glucopyranans Having Dodecyl Group in Position 3
}

\author{
Kazukiyo KoBAYASHI and Hiroshi SUmitomo \\ Faculty of Agriculture, Nagoya University, \\ Chikusa, Nagoya 464, Japan
}

(Received December 23, 1983)

\begin{abstract}
KEY WORDS Ring-Opening Polymerization / 1,6-Anhydro Sugar Derivatives / Synthetic Polysaccharide / 3-O-Dodecylated ( $1 \rightarrow 6)-\alpha$-DGlucopyranan / Glycolipid Model /
\end{abstract}

The synthesis of polysaccharides having long alkyl chains at relatively regular intervals was carried out. According to Scheme I, 1,6-anhydro-2,4-di- $O$-benzyl-3- $O$-dodecyl- $\beta$-D-glucopyranose (1) was copolymerized with 1,6-anhydro-2,3,4-tri- $O$-benzyl- $\beta$-D-glucopyranose (2), and the resulting copolymers 3 were debenzylated. The monomer 1 exhibited a high reactivity in terms of polymerization rate, monomer reactivity ratio, degree of polymerization, and stereospecificity. Debenzylation with sodium in liquid ammonia was successful for the copolymers of lower dodecyl content. A $(1 \rightarrow 6)-\alpha-D$-glucopyranan derivative was capable of forming a flexible, transparent membrane.

Such a well-defined modification can not be attained by direct alkylation onto polysaccharides. Not only regioselective alkylation but also uniform distribution of long alkyl group is difficult because the starting polysaccharides are poorly compatible with alkylation reagents.

The polysaccharides obtained can be regarded as a polymer model of glycolipids. Glycolipids are a major class of components of biological membranes. Synthetic glycolipids, especially those incorporated into liposomes, have proved a powerful tool for understanding

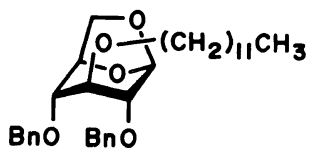

1

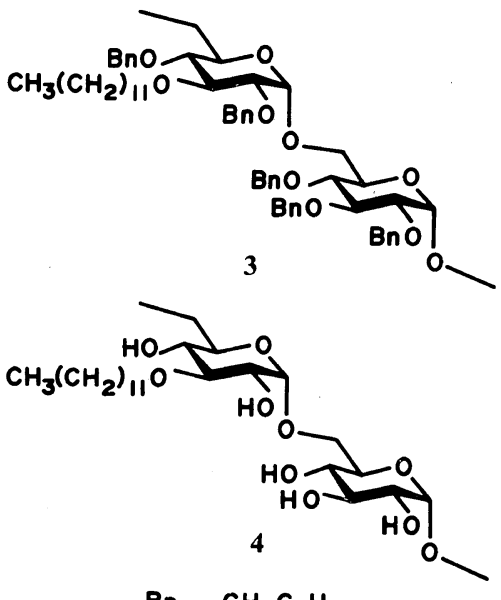

Bn, $\mathrm{CH}_{2} \mathrm{C}_{6} \mathrm{H}_{5}$

Scheme I carbohydrate-specific phenomena that occur at the cell surface. ${ }^{1-5}$ Polymer analogues of glycolipids have also been investigated to assemble highly stable liposomes. ${ }^{6,7}$ The polysaccharide synthesis via ring-opening polymerization $^{8}$ seem to be useful for this purpose. 


\section{EXPERIMENTAL}

\section{Characterization}

NMR spectra were recorded with a Japan Electron Optics Laboratory JNM-MH-100 NMR and a JNM-FX-100 Fourier transform NMR spectrometer. Tetramethylsilane was used as an internal standard in deuteriochloroform, dimethyl sulfoxide- $d_{6} \quad\left(\mathrm{Me}_{2} \mathrm{SO}-d_{6}\right)$, and dichloromethane. In the last solvent, deuterium oxide was used as an external lock. Optical rotations were determined in a JASCO DIP-181 digital polarimeter by using a $1-\mathrm{dm}$ cell. Viscosities were measured in Ubbelohde viscometers at $25^{\circ} \mathrm{C}$. Number-average molecular weights were determined by membrane osmometry using a Hewlett Packard 502 High Speed Membrane Osmometer. Toluene was employed as a solvent. Gel permeation chromatography was carried out by using a Shodex GPC-A-80M column (8-mm i.d. $\times 1000 \mathrm{~mm}$ ) on a Hitachi 634A high speed liquid chromatograph (solvent, chloroform). Thermal analysis was made by a Perkin Elmer DSC-2 differential scanning calorimeter with a heating rate at $10^{\circ} \mathrm{C} \mathrm{min}^{-1}$.

\section{Copolymerization}

1,6-Anhydro-2,4-di- $O$-benzyl-3- $O$-dodecyl$\beta$-D-glucopyranose (1) was prepared from 1,6anhydro-2,4-di- $O$-benzyl- $\beta$-D-glucopyranose and 1-bromododecane according to the method previously described. ${ }^{9}$ Viscous liquid; yield, $86 \% ;[\alpha]_{D}^{25}-23.4^{\circ}$ (chloroform, $1 \mathrm{~g} / 100 \mathrm{ml}$ ). Preparation of 2 and purification of dichloromethane and $p$-chlorobenzenediazonium hexafluorophosphate were followed in usual methods.

Copolymerization was carried out with a high vacuum technique according to the published procedures. An improved polymerization vessel was used to dry thoroughly the monomers. ${ }^{9,10}$ The polymerization was terminated by adding a cold mixture of methanol and petroleum ether. The precipitated polymer was purified by reprecipitation from chlo- roform solution into methanol-petroleum ether precipitant four times. Higher ratio of methanol/petroleum ether was used for the copolymers of higher content of 1 . A white powdery solid was obtained by freeze-drying from its benzene solution.

\section{Debenzylation}

Debenzylation of the copolymers using sodium-liquid ammonia was carried out as usual. A $3: 1(\mathrm{v} / \mathrm{v})$ mixture of toluene and dimethoxyethane was used as the solvent of the starting polymer. After $80 \mathrm{~min}$ of stirring at $-33^{\circ} \mathrm{C}$, anhydrous ammonium chloride was added until the blue color of the solution disappeared. Water $(30 \mathrm{ml})$ was added, ammonia was evaporated overnight, and the residue was treated with a mixture of water $(70 \mathrm{ml})$ and dichloromethane $(70 \mathrm{ml})$. The product was obtained from both the precipitate and the aqueous solution. The precipitate was collected on a glass filter, washed with methanol, and dissolved in $\mathrm{Me}_{2} \mathrm{SO}$. Removal of insoluble impurity by filtration through celite and reprecipitation of the filtrate into a large volume of methanol yielded a white powdery polymer. On the other hand, the aqueous solution was dialyzed, concentrated with a rotary evaporator, and freeze-dried to give a minor amount of powdery product.

\section{RESULTS AND DISCUSSION}

\section{Copolymerization}

Copolymerization between $\mathbf{1}$ and $\mathbf{2}$ was carried out under high vacuum at $-60^{\circ} \mathrm{C}$ in anhydrous dichloromethane. The polymerization conditions are summarized in Table I, which includes the data on the homopolymerization of 1 previously reported. ${ }^{9}$ Relatively large amount of phosphorus pentafluoride was used as the initiator. The homo- and copolymerization proceeded rapidly to reach a high conversion within $30 \mathrm{~min}$.

Table II lists characterizations of the resulting copolymers. The mole fraction of $\mathbf{1}$ in 
Partially 3-O-Dodecylated $(1 \rightarrow 6)-\alpha-\mathrm{D}-$ Glucopyranans

Table I. Copolymerization of 1,6-anhydro-2,4-di- $O$-benzyl-3- $O$-dodecyl-

$\beta$-D-glucopyranose (1) with 1,6-anhydro-2,3,4-tri- $O$ benzyl- $\beta$-D-glucopyranose $(2)^{\mathrm{a}}$

\begin{tabular}{|c|c|c|c|c|c|c|c|}
\hline \multirow{2}{*}{$\begin{array}{l}\text { Expl. } \\
\text { No. }\end{array}$} & 1 & 2 & \multirow{2}{*}{$\begin{array}{c}\text { Mole fraction } \\
\text { of } 1\end{array}$} & \multirow{2}{*}{$\frac{\text { Concn. }}{\mathrm{moll}^{-1}}$} & \multirow{2}{*}{$\begin{array}{l}\text { Mole ratio of } \\
\mathrm{PF}_{5} / \text { monomers }\end{array}$} & \multirow{2}{*}{$\frac{\text { Time }}{\min }$} & \multirow{2}{*}{$\frac{\text { Yield }}{\%}$} \\
\hline & $\mathrm{g}$ & g & & & & & \\
\hline $126^{\mathrm{b}}$ & 2.472 & - & 1.0 & 1.0 & 0.041 & 30 & 95.8 \\
\hline 129 & 0.989 & 0.839 & 0.50 & 0.65 & 0.052 & 12 & 64.3 \\
\hline 128 & 0.989 & 2.837 & 0.20 & 0.65 & 0.059 & 15 & 61.3 \\
\hline 127 & 0.494 & 3.768 & 0.10 & 0.69 & 0.052 & 24 & 76.6 \\
\hline
\end{tabular}

${ }^{\text {a }}$ Initiator, $\mathrm{PF}_{5}$; solvent, dichloromethane; temp, $-60^{\circ} \mathrm{C}$.

b Data from ref 9.

Table II. Characterization of copolymer 3

\begin{tabular}{|c|c|c|c|c|c|c|c|c|}
\hline $\begin{array}{c}\text { Sample } \\
\text { No. }\end{array}$ & $x^{\mathrm{a}}$ & $\frac{\mathrm{mp}^{\mathrm{b}}}{{ }^{\circ} \mathrm{C}}$ & $\frac{[\alpha]_{\mathrm{D}}^{25 \mathrm{c}}}{\operatorname{deg}}$ & {$[\eta]^{\mathrm{d}}$} & $M_{n} \times 10^{-5 \mathrm{e}}$ & $D P_{n} \times 10^{-2 \mathrm{e}}$ & $M_{n} \times 10^{-5 \mathrm{f}}$ & $M_{w} / M_{n}{ }^{\mathrm{f}}$ \\
\hline $126^{\mathrm{g}}$ & 1.0 & $<$ r.t. & 98.5 & 1.29 & 4.3 & 8.4 & 2.3 & 2.0 \\
\hline 129 & 0.48 & $\sim$ r.t. & 106.2 & 1.23 & 5.5 & 12 & 2.4 & 1.8 \\
\hline 128 & 0.19 & $32-36$ & 111.7 & 1.15 & 3.9 & 8.7 & 2.3 & 1.8 \\
\hline 127 & 0.11 & $45-48$ & 113.1 & 1.03 & 4.5 & 10 & 1.8 & 1.9 \\
\hline
\end{tabular}

a Mole fraction of 3-O-dodecyl unit in the copolymer.

b Determined by DSC. The melting point of the homopolymer corresponding to $x=0$ was $53-55^{\circ} \mathrm{C}$.

c Determined in chloroform; $c, 1 \mathrm{~g} / 100 \mathrm{ml}$.

d Determined in chloroform; $c, \mathrm{~g} / 100 \mathrm{ml} ; 25^{\circ} \mathrm{C}$.

e Membrane osmometry; toluene; $37^{\circ} \mathrm{C}$.

f GPC, polystyrene standard.

g Data from ref 9 .

copolymer, designated as $x$, was estimated from the area ratio of the alkyl signals $(\delta 1.25$ and 0.86$)$ and the phenyl signal $(\delta 7.20)$ in the ${ }^{1} \mathrm{H}$ NMR spectra. It was similar to or slightly less than the feed composition, indicating that the monomer reactivity ratio of $\mathbf{1}$ was comparable to that of $\mathbf{2}$.

Copolymers and respective homopolymers were soluble in benzene, toluene, carbon tetrachloride, chloroform, dichloromethane, dimethoxyethane, tetrahydrofuran, and pyridine. The solubility in the following solvents, however, changed with the copolymer composition. For example, the homopolymer of $\mathbf{1}$ was soluble in hexane and petroleum ether, but the copolymers were insoluble. In contrast, the homopolymer of $\mathbf{1}$ was insoluble in dimethyl- formamide (DMF), but the copolymers were soluble. In acetone, the copolymers of lower dodecyl content $(x=0.11$ and 0.19$)$ were soluble but those of higher dodecyl content ( $x=$ 0.48 and 1.0 ) were not.

The polymers obtained were of high molecular weight in spite of relatively large amount of the initiator used. The number average molecular weight determined by membrane osmometry ranged from $3.9 \times 10^{5}$ to $5.5 \times 10^{5}$, which corresponded to the degree of polymerization of about one thousand. The molecular weight estimated by GPC was smaller than that determined by membrane osmometry. Intrinsic viscosities were high and slightly increased with increasing $x$.

The DSC trace of the polymer of low do- 
K. Kobayashi and H. Sumitomo

Table III. Debenzylation of copolymer $3^{\text {a }}$

\begin{tabular}{|c|c|c|c|c|c|c|c|}
\hline \multirow{2}{*}{$\begin{array}{c}\text { Expt. } \\
\text { No. }\end{array}$} & \multirow{2}{*}{$x^{\mathbf{b}}$} & \multirow{2}{*}{$\frac{\mathrm{Na}}{\mathrm{g}}$} & \multirow{2}{*}{$\frac{\text { Solvent }}{\mathrm{ml}}$} & \multicolumn{2}{|c|}{ Yield $/ \%$} & \multirow{2}{*}{$\frac{[\alpha]_{D}^{25 c}}{\operatorname{deg}}$} & \multirow{2}{*}[\eta]{$^{\mathrm{d}}$} \\
\hline & & & & Water-sol. fr. & Water-insol. fr. & & \\
\hline $128 \mathrm{D}$ & 0.19 & 0.40 & 80 & 4 & 95 & $168^{\mathrm{e}}$ & $0.81^{\mathrm{e}}$ \\
\hline $127 \mathrm{D}$ & 0.11 & 0.59 & 40 & 4 & 88 & $180^{\mathrm{e}}$ & $0.69^{\mathrm{e}}$ \\
\hline
\end{tabular}

a Starting polymer, $1 \mathrm{~g}$; solvent, toluene-dimethoxyethane $(3: 1, \mathrm{v} / \mathrm{v})$; liquid ammonia, $100 \mathrm{ml}$; time $80 \mathrm{~min}$.

b Mole fraction of 3-O-dodecyl unit in the copolymer.

c Determined in $\mathrm{Me}_{2} \mathrm{SO} ; c, 1 \mathrm{~g} / 100 \mathrm{ml}$.

d Determined in $\mathrm{Me}_{2} \mathrm{SO} ; c, \mathrm{~g} / 100 \mathrm{ml} ; 25^{\circ} \mathrm{C}$.

e Water-insoluble fraction.

decyl content showed a narrow endothermic peak at the temperature listed in Table II. When the appearance of the polymer was examined with a hot-stage microscope using crossed polarizers, little change occurred at the temperature but the birefringence disappeared at a temperature range from 10 to $20^{\circ} \mathrm{C}$ higher than that listed (e.g., $58-69^{\circ} \mathrm{C}$ for the polymer No. 127). The reproducible value obtained from the DSC measurement was taken as the crystalline melting point. The melting point lowered with an increase of $x$. It may reflect that long alkyl chain disordered the regular arrangement of the tri- $O$-benzyl- $(1 \rightarrow 6)-\alpha$-Dglucopyranan chain.

High stereoregularity of the copolymers was suggested by optical rotations and ${ }^{13} \mathrm{C}$ NMR spectra. Specific rotations were high and their plots against the copolymer weight fraction gave a linear relationship. No observable ${ }^{13} \mathrm{C}$ NMR signal due to the $\beta$-anomeric structure appeared. All peaks of the copolymers were superimposable on peaks of one or the other homopolymers. ${ }^{9}$

High reactivity of $\mathbf{1}$ in terms of polymerization rate, monomer reactivity ratio, and degree of polymerization, and also high stereoregularity of the resulting polymers have been demonstrated. According to the mechanistic consideration as previously reported, ${ }^{11}$ the reactivity of 1,6-anhydro sugar derivatives decreased with an incorporation of a bulky substituent. It is reasonable to assume that a dodecyl ether chain is long but flexible and hence $\mathbf{1}$ has a similar reactivity to 2 .

\section{Partially 3-O-Dodecylated $(1 \rightarrow 6)-\alpha-D-G l u c o-$ pyranans}

The copolymers 3 of lower dodecyl content were debenzylated successfully by the conventional method using sodium in liquid ammonia (Table III). A large portion of the product was obtained as a water-insoluble precipitate, which was purified by reprecipitation of its $\mathrm{Me}_{2} \mathrm{SO}$ solution into methanol and used for the following characterizations. On the other hand, the water-extract of the reaction mixture contained only a small amount of the product, which was isolated by dialysis and freeze-drying. The polymer was designated as a water-soluble fraction in Table III although it became waterinsoluble after isolation.

Debenzylation of the polymers with higher dodecyl content was unsuccessful and the starting polymers were recovered. We assumed that the polymers could not come into close contact with solvated-electrons in liquid ammonia because of the poor compatibility between the long alkyl chain and the inorganic medium.

Figure 1 depicts the ${ }^{13} \mathrm{C}$ NMR spectrum of the product $(x=0.19)$ and the assignment. There appeared no signals due to the benzyl group and also the $\beta$-anomeric structure: complete debenzylation proceeded without ano- 


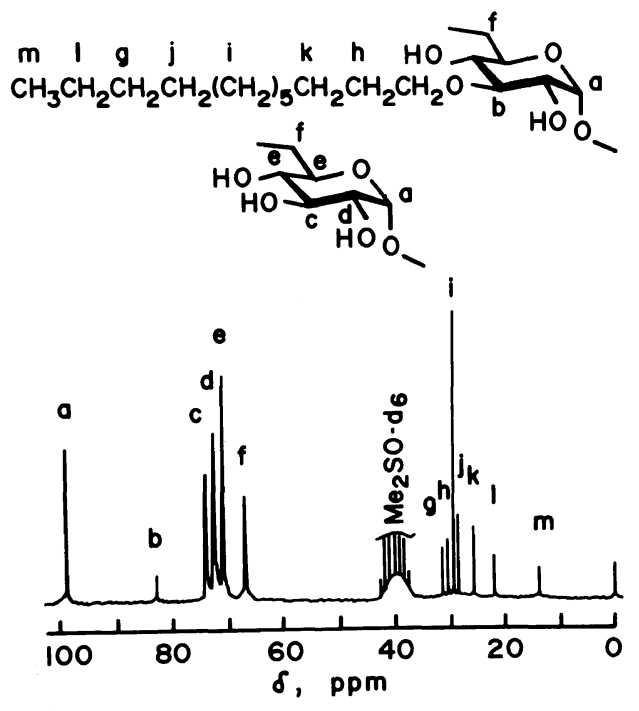

Figure 1. $25 \mathrm{MHz}{ }^{13} \mathrm{C} \mathrm{NMR}$ spectrum of 3- $O$ dodecylated $(1 \rightarrow 6)$ - $\alpha$-D-glucopyranan. Mole fraction of the dodecylated unit, 0.19 ; solv., $\mathrm{Me}_{2} \mathrm{SO}-d_{6}$; concentration, $9 \% 80^{\circ} \mathrm{C} ; 4500$ scans; $\mathrm{Me}_{4} \mathrm{Si}$ standard.

meric change. The absorptions at $\delta 31.13$ 13.67 (peak g-m) were ascribed to the alkyl carbons other than that adjacent to the ether oxygen. The $\mathrm{C}-3$ carbon of 3-O-dodecyl pyranose unit was also observed as an isolated peak at $\delta 82.20$ (peak b). The following assumption could be made on the basis of the assignment of partially 3-O-methylated $(1 \rightarrow$ 6)- $\alpha$-D-glucopyranans. ${ }^{10}$ The $\alpha$-anomeric C-1 carbon and C- 6 carbon of the dodecyl unit were overlapped with those of the unsubstituted unit at $\delta 98.25$ and 66.49 , respectively. Signals of the C-2, C-4, and C-5 pyranose carbons and the dodecyl methylene carbon adjacent to the ether oxygen were concealed behind the large peaks of the unsubstituted unit (peak c, d, and e).
The polymers were soluble in $\mathrm{Me}_{2} \mathrm{SO}$, $\mathrm{DMF}$, and pyridine. Both of the intrinsic viscosities and the specific rotations determined in $\mathrm{Me}_{2} \mathrm{SO}$ were high. The stereoregular and high molecular weight polysaccharides, partially 3-O-dodecylated $(1 \rightarrow 6)-\alpha$-D-glucopyranans, were obtained.

A flexible, transparent membrane of the copolymer of $x=0.19$ was prepared by casting from a $2 \%$ solution in $\mathrm{Me}_{2} \mathrm{SO}$ followed by immersing in water. Usually $(1 \rightarrow 6)-\alpha-D-$ glucans have no ability to form a stable membrane. Membrane formation has been attained by introduction of a long alkyl group.

\section{REFERENCES}

1. B. D. Read, R. A. Demel, H. Wiegandt, and L. L. M. van Deenen, Biochim. Biophys. Acta, 470, 325 (1977).

2. G. A. Orr, R. R. Rando, and F. W. Bangerter, $J$. Biol. Chem., 254, 4721 (1979).

3. R. R. Rando, J. Slama, and F. W. Bangerter, Proc. Natl. Acad. Sci. U.S.A., 77, 2510 (1980).

4. R. Y. Hampton, R. W. Holz, and I. J. Goldstein, J. Biol. Chem., 255, 6766 (1980).

5. P.-S. Wu, H.-M. Wu, G. W. Tin, J. R. Schuh, W. R. Croasmum, J. D. Baldeschwieler, T. Y. Shen, and M. M. Ponpipom, Proc. Natl. Acad. Sci. U.S.A., 79, 5490 (1982).

6. H. Bader, H. Ringsdorf, and J. Skura, Angew. Chem. Int. Ed. Engl., 20, 91 (1981).

7. J. Sunamoto, K. Iwamoto, T. Taguchi, and S. Murata, Polym. Prepr. Jpn., 31, 638 (1982).

8. C. Schuerch, Adv. Carbohydr. Chem. Biochem., 39, 157 (1982).

9. K. Kobayashi and H. Sumitomo, Nippon Kagaku Kaishi, 1633 (1982).

10. K. Kobayashi and H. Sumitomo, Macromolecules, 14, 250 (1981).

11. K. Kobayashi and C. Schuerch, J. Polym. Sci., Polym. Chem. Ed., 15, 913 (1977). 